\title{
Dural Reconstruction with or without A Bone Graft Following Oncologic Resections of Paranasal and Anterior Skullbase Malignancies
}

Björn Sommer ( $\sim$ bjoern.sommer@uk-augsburg.de )

University Hospital Augsburg: Universitatsklinikum Augsburg https://orcid.org/0000-0003-1717-2258

Ina Konietzko

Maximilian Niklas Bonk

Tina Schaller

Bruno Märkl

Klaus Henning Kahl

Georg Stüben

Johannes Zenk

Ehab Shiban

\section{Research Article}

Keywords: skull base tumor, resection, dural repair, complications, technique

Posted Date: February 21st, 2022

DOI: https://doi.org/10.21203/rs.3.rs-1316492/v1

License: (c) (i) This work is licensed under a Creative Commons Attribution 4.0 International License.

Read Full License 


\section{Abstract}

The reconstruction of frontobasal defects following oncologic resections of paranasal and anterior skull base malignancies remains challenging. Ineffective reconstruction could lead to cerebrospinal fluid leak, meningitis, and tension pneumocephalus. Aim of this investigation was to analyse postoperative complication rates with or without bone graft for anterior skull base reconstruction. In this retrospective study, we included patients following resection of paranasal and/or anterior skull base malignancies between October 2013 and November 2020. Complications were analysed with regards to the type of skull base reconstruction. Ten patients were identified ( 2 female, 8 male, age (median, SD) $65 \pm 14.8$ years (range 38 - 81). There were eight cases of paranasal sinus and nasal cavity carcinomas and two cases of olfactory neuroblastomas. Overall survival was $20 \pm 25.1$ months (range: $5-72$ ), progression free survival was $17.0 \pm 20.3$ months (range: $4-72$ ). Bone skull base reconstruction using a split graft was performed in three cases. Postoperative complications requiring surgical intervention were seen in $33 \%$ (one tension pneumocephalus) of cases in the bone reconstruction group and $57 \%$ (three patients with cerebrospinal fluid leak, one infection) in the non-bone reconstruction group. Additional bone reconstruction of the anterior skull base seems to lower the CSF leakage rate due to the additional abutment following resection of paranasal and anterior skullbase malignancies.

\section{Introduction}

Malignant tumors invading the anterior skull base, midface and sinonasal cavities are extremely rare with an incidence of approximately 0.6 to 0.8 per 100.000 population per year $[1,2]$. They account for $3-6 \%$ of malignancies of the head \& neck region $[3,4]$. The variety of histological subtypes and cell lines, rampant tumor growth and the complex anatomy of the affected structures require a multidisciplinary, highly specialized treatment. One cornerstone of current surgical therapy is a combination of endonasal, endoscopic and open transcranial/craniofacial techniques to maximise the extend of tumor mass reduction [5]. Surgical planning requires consideration of usage of a lumbar CSF drainage, pericranial and galea flaps, the type of donor graft materials such as autologous fat [6], temporalis fascia, fascia lata, or septal mucosa as a dural substitute [5]. Moreover, surgical remodelling can be achieved by a vascularized pedicled nasoseptal or pericranial flap [5], leading to a variety of combinations ultimately resulting in single-, double-, or triple layers of anterior skull base reconstruction. Complications include cerebrospinal fluid (CSF) leak, meningitis, intracranial abscess or tension pneumocephalus [7-9]. Depending on the size of the defect, especially when it involves a large portion of the cribriform plate and extending from the posterior table of the frontal sinus to the tuberculum sellae, rates of developing an encephalocele or CSF leak increase significantly [10]. Here, rigid structural grafting using cartilage, bone or titanium mesh are discussed controversially regarding reabsorption and potential risk of infection $[5,11,12]$. As no gold standard regarding surgical closure of large anterior skull base defects exist, we intended to evaluate the outcome and complication rates after anterior skull base reconstruction with or without bone graft in our departments. 


\section{Materials And Methods}

We conducted a retrospective study and screened patient databases of the Departments of Neurosurgery and Otolaryngology, Head and Neck Surgery in a 7-year period between 2013 and 2020. Inclusion criteria were a) tumor of the sinonasal cavity invading the anterior skull base and extending intracranially, b) interdisciplinary surgery in a one-stage setting, and c) skull base reconstruction with or without bone graft. Exclusion criteria were a) biopsy only, b) pregnancy, c) age $<18$ years. The responsible local ethics committee of the Ludwig-Maximilians-University Munich had no ethical concerns regarding this study (written request on January 10th 2022, personal communication). This retrospective study is in accordance with ethical principles for medical research involving human subjects as mentioned in the World Medical Association Declaration of Helsinki.

We obtained demographic data (age, sex), histological diagnosis, anatomical localization, progressionfree survival (PFS), overall survival (OS), completeness of resection according to early postoperative MRI scans, mortality, and surgery-associated early and late complications.

\section{Radiological features}

Every patient had CT, CT-angiography and MRI with and without contrast agent (gadolinum DPTA) for preoperative planning. Pre- and postoperative tumor volume (MRI T1 MPRAGE) as well as the size of the bony defect after resection was calculated using the software of our neuronavigaton system (Brainlab Elements ${ }^{\circledR}$, Brainlab AG, Munich, Germany). Due to the small sample size, no statistical test was performed.

\section{Operative techniques}

Two surgical techniques for skull base were performed in these patients. The operation was performed with a combined endonasal endoscopic resection of tumor mass by our otolaryngology surgeons. After resection of the ethmoid bone and parts of the tumor-invaded superior and middle turbinates, the resection is extended to the sphenoid sinus, removing the rhinobasis and the vomer. If the tumor mass invaded the orbita, an orbital extenteration was performed. Then, the neurosurgical team joined in and continued the operation via a transfrontal aproach. After bicoronal scalp incision, the scalp flap was reflected to the level of the supraorbital rim. A galea periost flap was prepared and bifrontal craniotomy with cranialization of the frontal sinuses was performed. The sagittal sinus was ligated and cut, the dura and falx cerebri were and flipped basally. After careful elevation of the frontal cortex, the anterior skull base with the remaining tumor mass, olfactory nerves and dorsally up to the optic chiasm is exposed. The tumor mass was resected and the whole tumor-infiltrated sphenoidal plane was exposed and if necessary, a decompression of the orbital roof performed (Fig. 1).

\section{Skull base reconstruction}


We used either a galea periost flap, which was sutured to the basal dura and fibrin glue. In three patients, a slit graft from the tabula externa was additionally inserted and fixed with titanium miniplates before the galea patch was sutured onto the dura (Fig. 2 and 3).

\section{Results}

We identified 209 patients that underwent surgical removal of frontal skull base malignancies in the observed time period. Of those, 10 fulfilled the inclusion criteria. Data regarding demographics, diagnosis, completeness of resection and PFS/OS are depicted in Table 1. A complete resection according to the first postoperative MRI and CT imaging was achieved in 8/10 patients. Pre- and postoperative data is summarized in Table 2. The bone defect of the anterior skull base was $13 \pm 4.8 \mathrm{~cm}^{2}$ (range: $7.5-16.2$ ). During the median follow-up period of 20 25.2 months (range: 5-72), tumor relapse was seen in 6 of 10 patients.

Complications occurred in $60 \%$ of all patients (Table 3), requiring early intervention and revision surgery in patients No. 5, 6, and 9. Late surgery due to a chronic rhiloliquorrhoe was necessary in patient No. 7 and due to hydrocephalus malresorptivus and concomitant intracranial abscess in patient N. 10 four and five months after initial surgery, respectively.

The mortality rate was $60 \%$ due to tumor progression or above-mentioned complications during the follow-up period.

\section{Discussion}

Even though the efficacy of chemotherapy and radiation therapy has improved over the past years, surgical resection remains the centerpiece of treatment in patients with advanced sinonasal tumors [13, 14]. Traditionally, a craniofacial resection was used to encounter sinonasal cancer invading the anterior skull base. Over time, endoscopic endonasal techniques revolutionized surgery of skull base and sinonsal malignancies [15-17]. To achieve the maximum extent of resection of skull base tumors, especially those with extensive antero-lateral involvement of the frontal sinus, dural infiltration of orbital roof, optic chiasm or brain parenchyma, a combined endoscopic and transcranial approach is recommended [18]. The surgical goal can be accomplished at the expense of the amount of dura which has to be resected. $A$ watertight dura closure remains a major goal to prevent from secondary complications such as meningitis, pneumocephalus and CSF loss over a fistula [9]. Here, endonasal as well as extracranial flaps can provide an effective reconstruction that seals and protects the brain parenchyma and CSF towards the skull base [19]. The remaining extensive cranial fossa defect should be restored with a counterpiece, just like an abutment, to prevent herniation, meningoencephalocele or osseous erosion due to chronic intracranial pressure put on the rim of the resected cavity. Here, several possibilities exist. The defect can be closed using autologous (tabula externa of the patients frontal craniotomy), allogenic (cadaveric) bone, PEEK or titan mesh grafts, which is fastened with mini-plates and screws $[5,9,12]$. Bone graft failure, especially after postoperative radiation therapy including aseptic bone necrosis, extrusion of the 
hardware or secondary infection due to CSF leaks are reported in 5 to $15 \%[20,21]$. Of note, nine out of 10 patients had a skull base defect $>10 \mathrm{~cm}^{2}$ in our patient cohort, indicating that a larger proportion of abutment is missing after resection of anterior skull base malignancies.

Others use a tensor facial lata patch, muscle and fat reinforced by a vascularized pericranium only and omit any additional solid material $[6,12,17]$. Drawback of autologous grafts are their reabsorption due to the continuous brain pulsation, their limitation in size to cover large defects, or risk of secondary infection $[5,22]$. CSF leaks can occur in around 8 to $28 \%$ in open surgical and endoscopic cases $[5,7,8]$. The use of a lumbar drainage is discussed controversely. On the one hand, it should aid in relieving intracranial pressure in the sites of dural adaptation and closure to faciliate the creation of a closed extra/intracranial barrier. On the other hand, additional CSF drainage can lead to a pneumatocephalus as in one of our patients $[8,9,23]$. In our case series, no encephalocele was noticed during the follow-up period. Surgeryrelated complications that occurred in the early phase of the hospital stay were more frequent in patients without a bone graft. No CSF leakage occurred in this group, either, although every patient received a lumbar drainage.

\section{Limitations}

Due to the small sample size and the retrospective nature of this study, no general recommendation can be drawn from our results. A statistical analysis could not be performed, and the group sizes were different indicating a potential selection bias. Possible confounders such as experience of the neurosurgeon and otolaryngology surgeon or the water-tightness between the layers of primary dural reconstruction cannot be ruled out.

\section{Conclusion}

If an area $>10 \mathrm{~cm}^{2}$ of the anterior skull base is destroyed by sinonasal cancer, bone reconstruction of the anterior skull base seems to be associated with lower CSF leakage rates following resection of paranasal and anterior skullbase malignancies.

\section{Declarations}

\section{Funding:}

The authors declare that no funds, grants, or other support were received during the preparation of this manuscript.

\section{Conflict of interest:}

The authors have no relevant financial or non-financial interests to disclose.

\section{Availability of data and material:}


Anonymized data sets can be provided electronically upon request.

\section{Code availabity:}

Not applicable.

\section{Ethics approval:}

This is an observational study. The responsible local ethics committee of the Ludwig-MaximiliansUniversity Munich had no ethical concerns regarding this study (written request on January $10^{\text {th }} 2022$, personal communication).

\section{Author contributions:}

Experimental design, collection and interpretation of data, analysis of data, writing of the draft manuscript: B.S.

Experimental design, collection and interpretation of data: I.K., M.N.B., B.M., T.S.

Experimental design, implementation, analysis and interpretation of data, correction of draft manuscript, approval of final version: E.S.

Correction of draft manuscript, approval of the final version: J.Z., E.S., B.M., T.S., K.H.K, G.S.

\section{Consent to participate:}

All patients or their relatives in case of passing away gave their informed consent to include the anonymized data in this study.

\section{Consent for publication:}

All patients or their relatives in case of passing away gave their informed consent to publish the anonymized data of this study.

\section{References}

1. Turner JH, Reh DD (2012) Incidence and survival in patients with sinonasal cancer: a historical analysis of population-based data. Head Neck 34:877-885.

2. Dutta R, Dubal PM, Svider PF, Liu JK, Baredes S, Eloy JA (2015) Sinonasal malignancies: a population-based analysis of site-specific incidence and survival. Laryngoscope 125:2491-2497.

3. Albonette-Felcio T, Rangel GG, Martinéz-Pérez R, Hardesty D, Carrau RL, Prevedello DM (2020) Surgical management of anterior skull-base malignancies (endoscopic vs. craniofascial resection). $J$ Neurooncol 150:429-436. 
4. Marinelli JP, Janus JR, Van Gompel JJ, Link MJ, Foote RL, Lohse CM, Price KA, Chintakuntlawar AV (2018) Esthesioneuroblastoma with distant metastases: systematic review \& meta-analysis. Head Neck 40:2295-2303.

5. Eloy JA, Marchiano E, Vázquez A, Pfisterer MJ, Mady LJ, Baredes S, Liu JK (2017) Management of skull base defects after surgical resection of sinonasal and ventral skull base malignancies. Otolaryng Clin N Am 50:397-417.

6. Bohoun CA, Goto T, Morisako H, Nagahama A, Tanoue Y, Ohata K (2019) Skull base dural repair using autologous fat as a dural substitute: an efficient technique. World Neurosurg 127:e896-900.

7. Sokoya M, Mourad M, Ducic Y (2017) Complications of skull base surgery. Semin Plast Surg 31:227230.

8. Gata A, Toader C, Trombitas VE, llyes A, Albu S (2021) Endoscopic skull base repair strategy for CSF leaks assoiated with pneumatocephalus. J Clin Med 10:46.

9. Reinard K, Basheer A, Jones L, Standring R, Lee I, Rock J (2015) Surgical technique for repair of complex anterior skull base defects. Surg Neurol Int 6:20.

10. Eloy JA, Shukla PA, Choudhry OJ, Singh R, Liu JK (2012) Assessment of frontal lobe sagging after endoscopic endonasal transcribriform resection of anterior skull base tumors: is rigid structural reconstruction of the cranial base defect necessary? Laryngoscope 122:2652-2657.

11. Kwon SG, Kim YO, Rah DK (2012) Anterior cranial base reconstruction with a reverse temporalis muscle flap and calvarial bone graft. Arch Plast Surg 39;345-351.

12. He J, Lu J, Zhang F, Chen J, Wang Y, Zhang Q (2021)The treatment strategy for skull base reconstruction for anterior fossa intra- and extracranial tumors. J Craniofac Surg 32:1673-1678.

13. Abu-Ghanem S, Shilo S, Yehuda M, Abergel A, Safadi A, Fliss DM (2020) Anterior skull base surgery in the 21st century: the role of open approaches Adv Otorhinolaryngol 84:56-67.

14. Yong M, Wu YQ, Su S, Hanna E, Prismann E, Thamboo A, Walgama E (2021) The effect of prior radiation on the success of ventral skull base reconstruction: a systematic review and meta-analysis. Head \& Neck 43:2795-2806.

15. Yeung JT, Caminer DM, Young IM, Sughrue ME, Teo C (2021) Radical exenteration of the skull base for end-stage, locally advanced sinonasal malignancies: challenging the dictum of unresectability. Wolrd Neurosurgery 150:e102-e107.

16. Guazzo E, Bowman J, Porceddu S, Webb L, Panizza B (2019) Advanced cystic carcinoma of the skull base - the role of surgery. Oral Oncol 99:104466.

17. Buchmann L, Larsen C, Pollack A, Tawfink O, Sykes K, Hoover LA (2006) Endoscopic techniques in resection of anterior skull base/paranasal sinus malignancies. Laryngoscope 116:1749-1754.

18. Castelnuovo P, Turri-Zanoni M, Battaglia P, Antognoni P, Bossi P, Locatelli D (2016) Sinonasal malignancies of anterior skull base: histology-driven treatment strategies. Otolaryngol Clin North Am 49:183-200. 
19. Moon JH, Kim EH, Kim SH (2019) Various modifications of a vascularized nasoseptal flap for repair of extensive skull base defects. J Neursurg 132:371-379.

20. Janecka IP (2000) New reconstructive technologies in skull base surgery. Arch Otolaryngol Head Neck Surg 126:396-401.

21. Garcia-Navarro V, Anand VK, Schwart TH (2013) Gasket seal closure for extended endonasal ensdoscopic skull base surgery: efficiacy in a large case series. World neurosurg 80:563-568.

22. Gil Z, Abergel A, Leider-Trejo L, Khafif A, Margalit N, Amir A, Gur E, Fliss DM (2007) A comprehensive algorithm for anterior skull base reconstruction after oncological resections. Skull Base 17:25-37.

23. Vrionis FD, Kienstra MA, Rivera M, Padhya TA (2004) Malignant tumors of the anterior skull base. Cancer Control 11:144-151.

\section{Tables}

Tables are available in Supplementary files section.

\section{Figures}
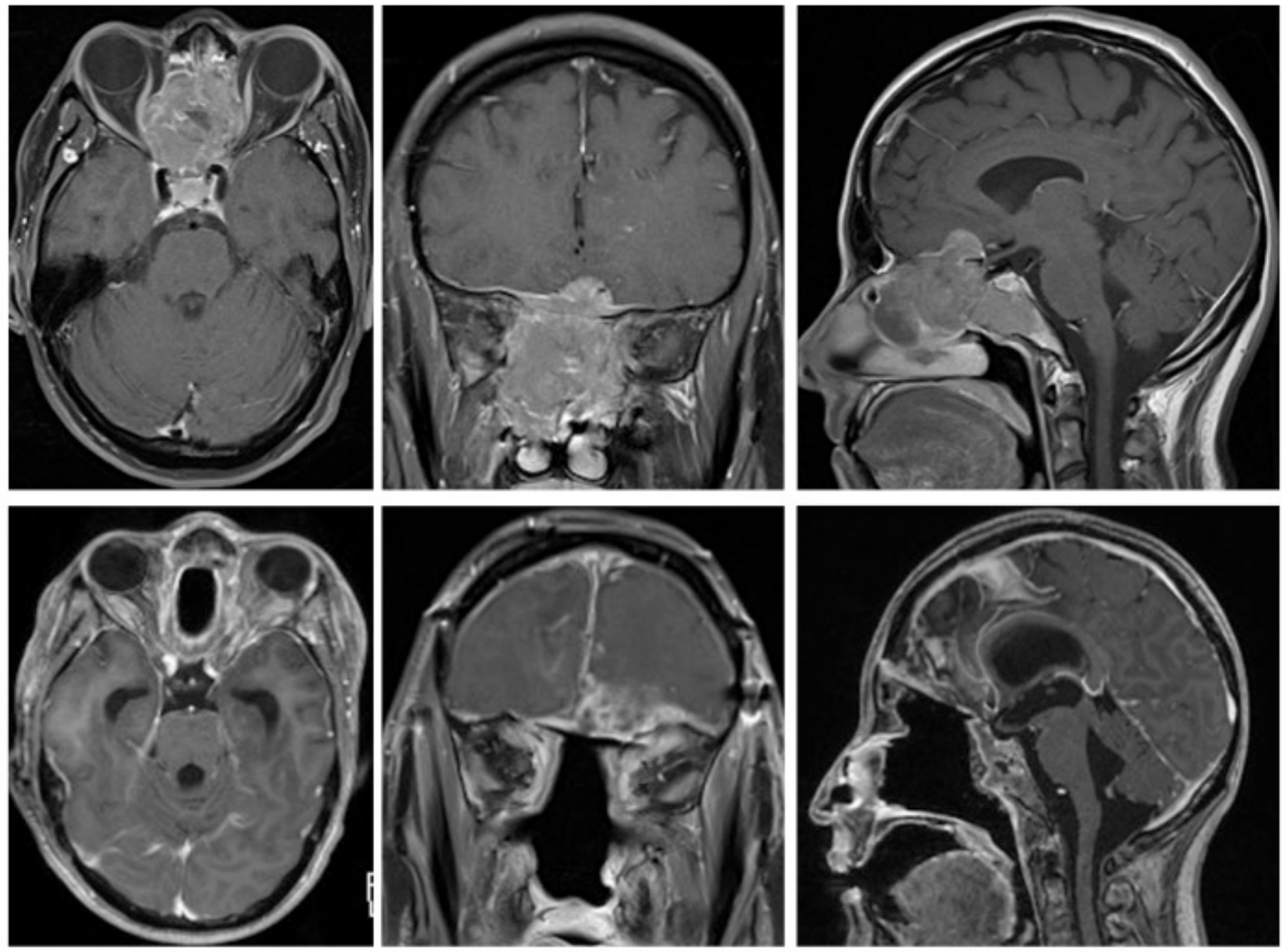


\section{Figure 1}

Pre- (top row) and postoperative (bottom row) MRI scans (transversal, coronal, axial) with GadoliniumDTPA contrast agent depicting the sinonasal and frontobasal esthesioneuroblastoma of pat. No. 10. Residual tumor mass can be seen in the left superior part of the periorbita.

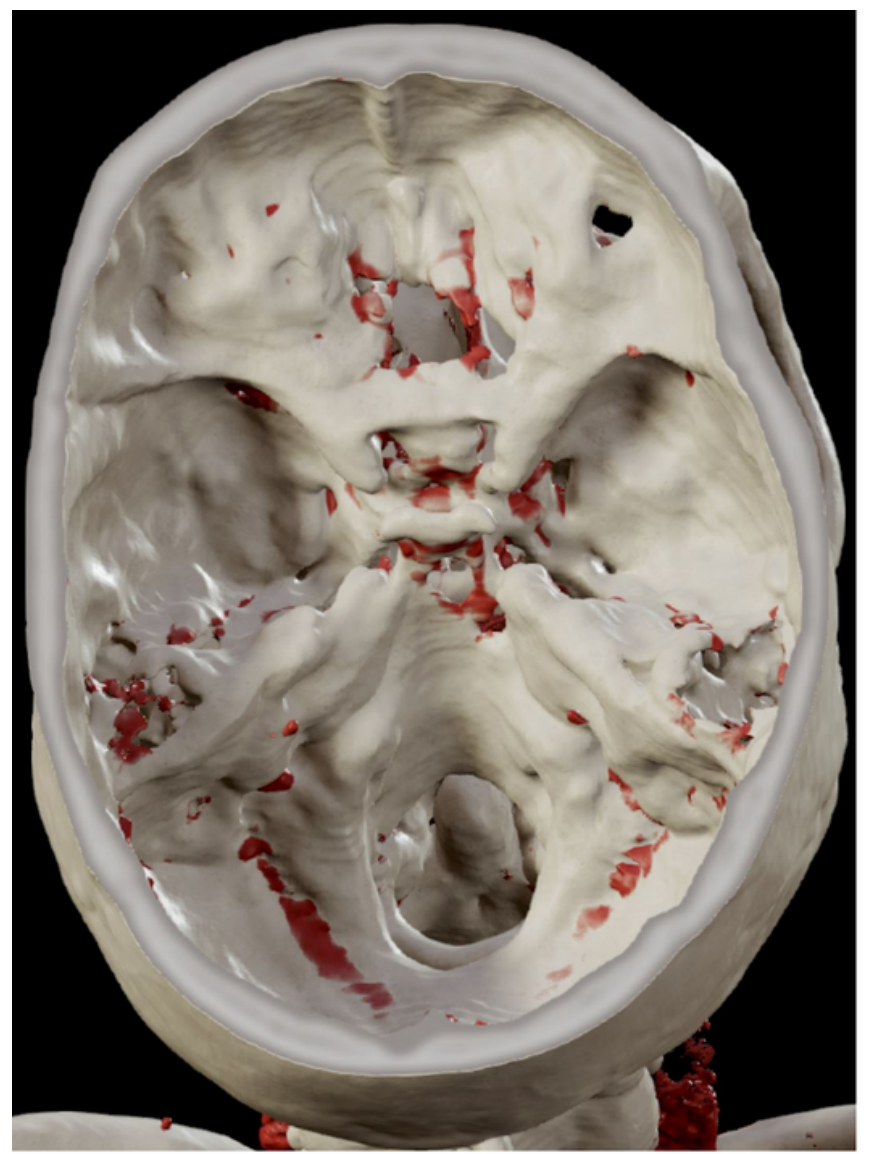

A

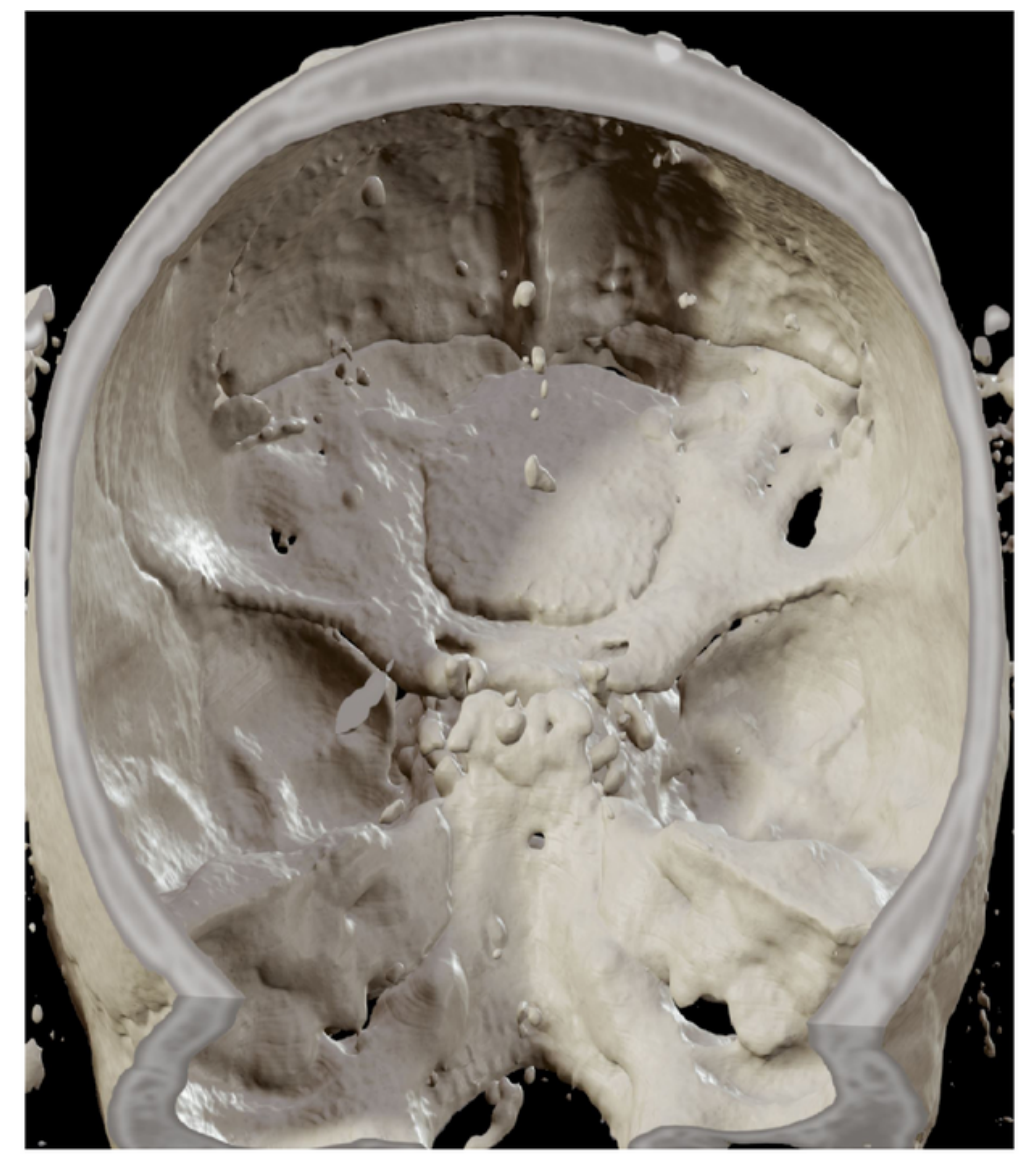

B

Figure 2

Pre- (Fig. 2 A) and postoperative (Fig. 2 B) CT scans showing a 3D-reconstruction of the frontobasal bone defect of patient No. 10, which was covered with an autologous tabula externa bone chip. 


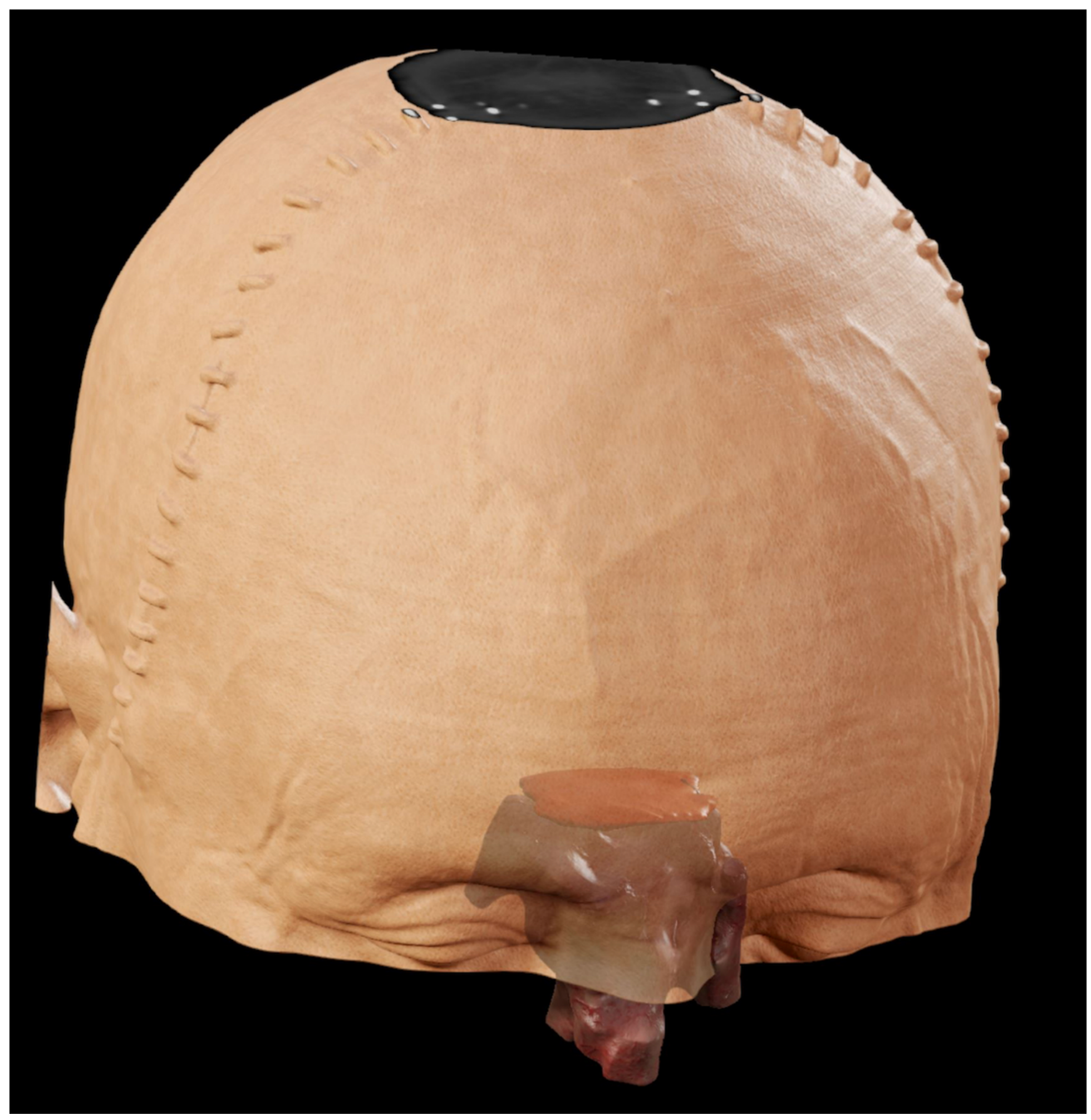

Figure 3

Virtual visualization of the tumor mass (red) and the implanted bone chip (orange).

\section{Supplementary Files}

This is a list of supplementary files associated with this preprint. Click to download. 
- DuralReconSBTUTab127012021.xIsx

- DuralReconSBTUTab227012022.xIsx

- DuralReconSBTUTab327012022.xlsx 